\title{
Coupling of Nanofiltration and Thermal Fenton Reaction for the Abatement of Carbamazepine in Wastewater
}

\author{
Marco Minella, ${ }^{\dagger}$ Nicola De Bellis, ${ }^{\dagger}$ Andrea Gallo, ${ }^{\ddagger}$ Mattia Giagnorio, ${ }^{\ddagger}$ Claudio Minero, ${ }^{\dagger}$ \\ Stefano Bertinetti, ${ }^{\dagger}$ Rajandrea Sethi, ${ }^{\ddagger}$ Alberto Tiraferri, ${ }^{*},+(0)$ and Davide Vione ${ }^{*}, \dagger, \S(0)$ \\ ${ }^{\dagger}$ Department of Chemistry, University of Torino, Via P. Giuria 5, Torino 10125, Italy \\ ${ }^{\ddagger}$ Department of Environment Land and Infrastructure Engineering (DIATI), Politecnico di Torino, Corso Duca degli Abruzzi 24, \\ Torino I-10129, Italy \\ ${ }^{\S}$ University of Torino, NatRisk Inter-Department Centre, Largo P. Braccini 2, Grugliasco, 10095 Torino, Italy
}

\section{Supporting Information}

\begin{abstract}
The complete removal of biorecalcitrant xenobiotics, including most notably the pharmaceutical pollutants, by advanced oxidation processes is often difficult to be reached in urban or industrial wastewater because of the high concentration of organic and inorganic scavengers that compete with the xenobiotics for the oxidizing species. This work investigates a coupled treatment train in which wastewater effluents are pretreated with a negatively charged loose nanofiltration (NF) membrane (HydraCoRe70, made up of sulfonated polyethersulfone) to enhance the removal of xenobiotics with the thermal Fenton process. Carbamazepine (CBZ), a drug prescribed mainly for epilepsy treatment, is used here as a model xenobiotic. After optimizing the conditions for separation and degradation, the NF-Fenton approach was applied to both synthetic wastewater and real samples to assess the overall efficiency of CBZ removal. The Fenton degradation of CBZ was drastically enhanced in nanofiltered samples, thanks to the removal by the membrane of nearly all organic matter that would otherwise consume the reactive oxidizing species (e.g., the hydroxyl radical). On the basis of a preliminary treatment cost analysis, it can be concluded that the combined process is potentially applicable to the treatment of several kinds of wastewaters (e.g., industrial ones) to favor the removal of biorecalcitrant contaminants. Key cost savings of NF-Fenton concern the lower amounts of Fenton reagents needed to degrade CBZ and (even more importantly) the decreased levels of acids and bases for $\mathrm{pH}$ adjustment before and after the oxidative process because of the lower buffer capacity of the NF permeate compared to feed wastewater, after the removal by the NF of many inorganic ions and most organic carbon.
\end{abstract}

\section{INTRODUCTION}

The main scientific and technological efforts in the field of wastewater treatment (urban or industrial) have been focused in the past on the implementation of plants able to reach a total abatement of the main macropollutants. ${ }^{1}$ In this context, the widely applied technologies based on the activated sludge are able to satisfy the most recent legislations for the preservation of water resources. However, the attention of the scientific community in the field of water treatment has recently shifted to the ubiquitous occurrence of micro- and biorecalcitrant contaminants in water environments. These compounds are not or are only partially removed by the conventional wastewater treatment plants (WWTPs), which has raised concern in several governmental authorities around the world. ${ }^{2,3}$ The European Union has recently proposed the first Watch List of compounds that pose a risk to the aquatic environment, based on in-depth comparative studies of the most recent literature regarding the ecotoxicological features of the most abundant micropollutants. ${ }^{4}$ Furthermore, the only partial abatement of micropollutants by the traditional
WWTPs hinders a safe reuse of the water after treatment (e.g., for agriculture). This issue limits the resilience of human societies that live in environments where water resources are either scarce or will become so as a consequence of climate change. In the absence of a total removal of micropollutants, the need to close the water cycle to save water would in fact magnify the concentration of these compounds and cause problems to both human health and natural ecosystems.

Among the possible strategies to technologically update the existing WWTPs, the ability of the advanced oxidation processes (AOPs), and particularly of the Fenton reaction, is well documented to remove many recalcitrant pollutants from both urban and industrial wastewater. ${ }^{5-7}$ The most common interpretation of the mechanism of the Fenton reaction is based on the proposal by Haber and Weiss and successive modifications. ${ }^{8}$ The starting process involves $\mathrm{Fe}(\mathrm{II})$ and $\mathrm{H}_{2} \mathrm{O}_{2}$

Received: May 18, 2018

Accepted: August 2, 2018

Published: August 17, 2018 
that generate hydroxyl radicals, which are able to promote pollutant degradation. The Fenton reaction is mainly a twostep process, with a first and kinetically fast step (ferrous step) consisting in the oxidation of $\mathrm{Fe}(\mathrm{II})$ to $\mathrm{Fe}(\mathrm{III})$ by $\mathrm{H}_{2} \mathrm{O}_{2}$ to produce ${ }^{\circ} \mathrm{OH}$, followed by a slower second step (ferric step) in which $\mathrm{Fe}$ (II) is regenerated, accounting for the catalytic nature of the overall process. 9,10

Several strategies have been proposed to speed up the slow (ferric) step of the Fenton reaction and to increase the overall rates of pollutant degradation, including the electron-Fenton process where $\mathrm{Fe}(\mathrm{III})$ reduction is carried out at the surface of a cathode, ${ }^{11-13}$ the use of sacrificial reductive agents, ${ }^{9,14-16}$ as well as the photo-Fenton reaction, with ${ }^{17,18}$ or without iron ligands. ${ }^{19-21}$ In the photo-Fenton reaction, the absorption of light by $\mathrm{Fe}^{\mathrm{III}} \mathrm{OH}^{2+}$ or $\mathrm{Fe}^{3+}-\mathrm{L}$ complexes (where $\mathrm{L}=$ organic ligand) promotes $\mathrm{Fe}(\mathrm{III})$ reduction with the production of, respectively, ${ }^{\bullet} \mathrm{OH}$ or $\mathrm{L}^{\bullet+}$. The real nature of the reactive species in the Fenton process has long been debated, but a concomitant or alternative role of ${ }^{\bullet} \mathrm{OH}$ and superoxidized iron species is usually proposed (e.g., ferryl ion $\mathrm{FeO}^{2+}$ or even $\mathrm{Fe}(\mathrm{V})$ and $\mathrm{Fe}(\mathrm{VI})$ compounds $\left.\mathrm{s}^{102-24}\right)$. The difficulties related to the discrimination between ${ }^{\circ} \mathrm{OH}$ and high-valent iron species, which often produce or are supposed to produce the same byproducts or react with the same "selective" scavengers, have prevented conclusive mechanistic considerations to be reached.

Irrespective of the actual reaction mechanism, some major drawbacks of the Fenton treatment when applied to wastewater are as follows: (i) the need to operate under acidic conditions, the optimal $\mathrm{pH}$ value for Fenton degradation ${ }^{25}$ being usually around 3 , with the associated costs to adjust the $\mathrm{pH}$ for treatment and back-adjust it to $\sim$ neutral conditions before discharging the treated effluent; (ii) the precipitation of a $\mathrm{Fe}$ (III) slurry in the final basification step, with the subsequent need to separate the solid from the aqueous phase, and (iii) the occurrence in the wastewater of the species that can compete with the pollutant(s) for the reaction with the oxidizing transients, such as the dissolved organic matter (DOM) and inorganic ions such as $\mathrm{HCO}_{3}{ }^{-}, \mathrm{CO}_{3}{ }^{2-}, \mathrm{Cl}^{-}, \mathrm{Br}^{-}$, and $\mathrm{NO}_{2}{ }^{-26}$ Possible solutions to tackle these drawbacks are as follows:

(a) The immobilization of the iron centers on solid supports $^{27,28}$ or the use of iron-based solid materials as sources of iron, such as magnetite, ${ }^{29-31}$ hematite, ${ }^{32,33}$ as well as zero-valent iron. ${ }^{29,34,35}$ These solid materials can be recovered at the end of the process, for example, through their magnetic properties and reused;

(b) The implementation of Fenton-like reactions based on the production of reactive transients that are more selective toward the pollutant to be degraded, such as the sulfate radicals $\mathrm{SO}_{4}{ }^{\bullet-}$. These transients are generated from $\mathrm{S}_{2} \mathrm{O}_{8}{ }^{2-}$ instead of $\mathrm{H}_{2} \mathrm{O}_{2}$. They react with similar kinetics as ${ }^{\bullet} \mathrm{OH}$ toward aromatics but are less scavenged by natural $\mathrm{DOM} ;^{36,37}$

(c) The coupling of the Fenton reaction with a separation step able to selectively remove the compounds that scavenge the reactive transients. Separation and degradation are in fact complementary mechanisms to purify water, and they may be applied in synergy to ensure a water effluent of high quality.

Among the advantages of membrane processes compared to other water treatment techniques, one can enumerate modular composition, low energy requirements, and no or little need to add chemicals. ${ }^{38}$ While membranes perform the selective removal of contaminants, other treatment methods can be applied to degrade hazardous substances and to inactivate microorganisms. Few studies have proposed the integration of membrane filtration systems with different water treatment processes. $^{39-41}$ Two examples of such integration are the coupling of coagulation and flocculation with microfiltration in membrane bioreactors and the combination of catalytic/AOPs with nanofiltration (NF). In recent years, the latter systems have been studied to achieve micropollutant abatement in wastewater treatment. ${ }^{42-44}$ The cited research studies have highlighted the potential and the problems associated with the polishing of the NF retentate stream by the application of AOPs, such as Fenton oxidation. Specifically, high concentration of the organic matter was shown to significantly reduce the oxidation efficiency because of the scavenging of hydroxyl radicals, which increases the demand of reagents to sustain oxidation. To cope with this drawback, AOPs may be instead applied to the permeate stream produced by the NF treatment of wastewater. In this configuration, low-pressure NF removes organic matter and other scavengers from wastewater, thereby enhancing the cost- and energy efficiency of the AOP oxidation of the effluent containing the micropollutants. In this work, the efficacy of this novel approach is investigated by using a membrane separation to selectively eliminate the interfering agents of the Fenton process.

In this framework, this work was aimed at (i) exploring and evaluating the potential coupling of a highly negatively charged, sulfonated polyethersulfone loose NF membrane with a thermal Fenton process (the wastewater effluent was treated by NF, followed by Fenton), to treat wastewater with different amounts of organic carbon (as representative samples, we chose urban wastewaters at two different stages of the depuration process) and (ii) assessing treatment costs to verify the feasibility of the coupled technology in real-world applications. The main novelty of our study lies in the effective coupling of the two systems, with the aim to prove that this coupling is feasible and does not involve special operation on either treatment step. Indeed, we tested the two processes in conventional operation to explore their scalability.

\section{RESULTS AND DISCUSSION}

Removal of Compounds by NF. NF is proposed in this study as a separation process in wastewater treatment to remove dissolved and suspended organic macromolecules. The removal of organic macromolecules allows for the achievement of low chemical oxygen demand and total organic carbon (TOC) values in the effluent. The main hypothesis to be tested is that NF acts as an effective pretreatment step to maximize the efficiency and to decrease the costs associated with the Fenton reaction, applied to remove recalcitrant micropollutants from wastewater.

The properties of the two real wastewater samples investigated in this work are reported in the Experimental Section. These samples are denoted hereafter as Primary sample and Secondary sample. Figure 1 summarizes the main experimental results obtained in laboratory NF tests, by the application of Hydra70 membranes. The latter were used to treat either synthetic feed waters containing model macromolecules such as humic acids (HAs), sodium alginate (Alg), and bovine serum albumin (BSA) or an effluent (Primary and Secondary sample) from an urban WWTP facility. All of the 
A

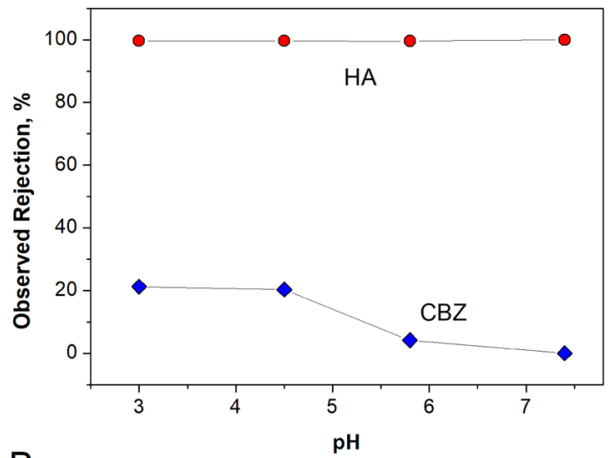

B

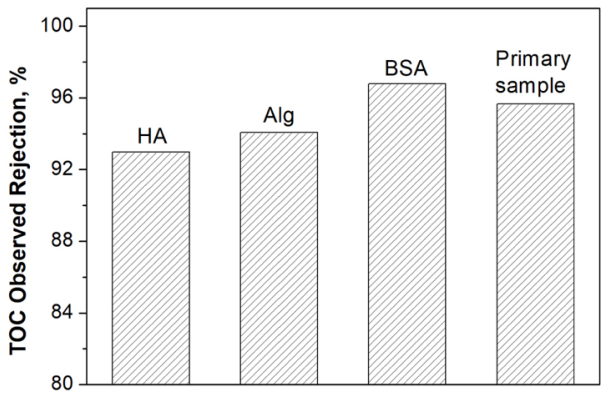

C

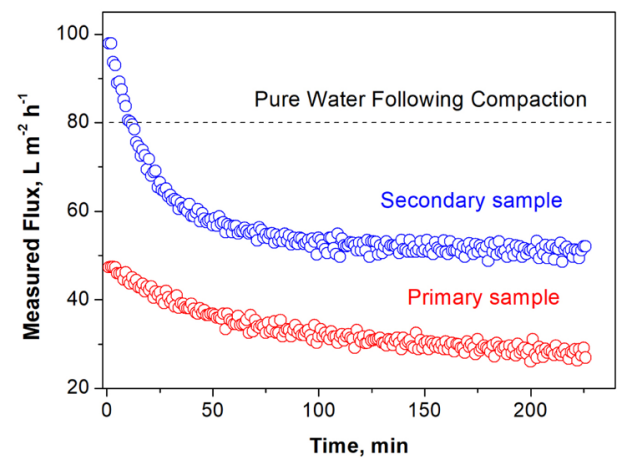

Figure 1. Results of membrane (Hydra70) separation tests with synthetic and real feed water streams. (A) Rejection of HAs and CBZ as a function of $\mathrm{pH}$, in a feed solution containing a mixture of salts and mimicking a typical wastewater effluent. (B) TOC rejection obtained with feed waters containing different organic macromolecules and with the Primary sample at $\mathrm{pH}$ 7.4. (C) Permeate fluxes determined when treating Secondary and Primary sample during the initial $2.5 \mathrm{~h}$ of treatment at an applied pressure of $300 \mathrm{psi}$; the dotted line is the steady-state value obtained with pure water. All experiments were performed at a feed water temperature of $22{ }^{\circ} \mathrm{C}$.

feed waters were spiked with carbamazepine (CBZ). The Hydra70 membrane completely removed HAs regardless of the $\mathrm{pH}$ of the feed solution, whereas the removal of CBZ was always lower than $25 \%$ and displayed a decreasing trend with increasing $\mathrm{pH}$. In particular, the removal of $\mathrm{CBZ}$ was negligible at $\mathrm{pH}>7$ (Figure 1a). These results are explained by a major contribution of size exclusion in the removal of HAs, and size exclusion is evidently not affected by HA protonation at acidic $\mathrm{pH}$ (humic substances are weak polyelectrolytes). CBZ is a neutral molecule across the entire $\mathrm{pH}$ range investigated in this study, and the observed increase in its rejection at $\mathrm{pH}<6$ may be rationalized as enhanced hydrophobic interactions with HAs. Indeed, HAs are expected to become progressively less charged as the $\mathrm{pH}$ decreases, which enhances interaction with neutral CBZ and leads to rejection by the membrane surface of the CBZ molecules involved into associations with HAs. This study suggests that the application of loose $\mathrm{NF}$ in $\sim$ neutral $\mathrm{pH}$ conditions causes near complete removal of HAs, together with negligible removal of CBZ. This behavior is very interesting because it allows for the abatement of interfering agents from the effluent, while simultaneously avoiding the concentration of $\mathrm{CBZ}$ in the NF retentate stream that would otherwise require a dedicated micropollutant treatment for safe disposal. Indeed, previous studies using highly selective polyamidebased NF membranes to remove pharmaceuticals from municipal wastewater showed rejection rates larger than $97 \%$ for $\mathrm{CBZ}$, flumequine, and ibuprofen, but they highlighted that high amounts of Fenton reagents were then needed to degrade these compounds in the retentate stream. ${ }^{42,43}$ In addition, the use of more selective membranes for the removal of small molecules such as CBZ entails higher energy consumption, as well as highly increased problems connected with fouling (Baker, 2012).

Analogous results were obtained by using feed solution waters containing different representative organic macromolecules or actual effluents (i.e., Primary sample and Secondary sample), all spiked with CBZ (see Figure 1b). The rejection of the TOC by the Hydra70 membrane was always above $90 \%$ at $\mathrm{pH} 7.4$, whereas the rejection of $\mathrm{CBZ}$ was always lower than $5 \%$ (data not shown). These values suggest near complete rejection of large organic macromolecules regardless of their nature, which removes potential Fenton interfering agents from the effluent and may help in the optimization of the subsequent oxidation step. Our results are consistent with those obtained in previous studies where NF was proven to be an efficient technology for the removal of organic molecules from wastewater, with rejection rates always higher than $85 \%{ }^{45,46}$ Fouling was shown to be the main drawback in these applications, decreasing the permeate flux in accordance with the results presented in Figure 1.

The steady-state values of the permeate flux obtained when treating the primary effluent were in the range of $25-30 \mathrm{~L} \mathrm{~m}^{-2}$ $\mathrm{h}^{-1}$ (LMH) at an applied pressure of $300 \mathrm{psi}(20.7 \mathrm{bar})$. As shown in Figure 1c, the permeate flux decreased rapidly in the first part of the test because of (i) membrane compaction, (ii) the initial accumulation of fouling substances on the membrane surface, and (iii) the establishment of an osmotic pressure profile at the membrane/feed interface. The value of permeate flux at the steady state for the Primary sample was approximately three times lower than that obtained with pure water, and it was half of the flux that was observed during the treatment of the Secondary sample. The Secondary sample, less loaded with organic materials and suspended solids compared with the Primary sample, was in fact also assessed for comparison. The range of permeate flux observed when treating the primary effluent is suitable for a cost-effective purification of this stream, if accompanied by a correct management of the membrane system as discussed in the technoeconomic assessment of the proposed treatment train (vide infra).

Coupling of NF and the Fenton Reaction for CBZ Degradation in Synthetic Solutions. The first experiments of Fenton CBZ degradation had the goal of optimizing the conditions to reach a complete substrate removal in the desired reaction time $(\leq 30 \mathrm{~min})$. Both the pure Fenton experiments and the NF-Fenton coupling tests were initially carried out with a CBZ concentration $\left(C_{o}=10 \mathrm{ppm}\right)$ higher than usually found in real samples. The main rationale for this choice was to 
A

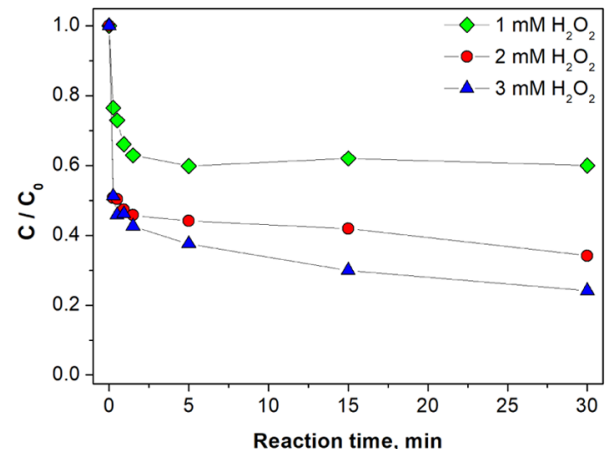

B

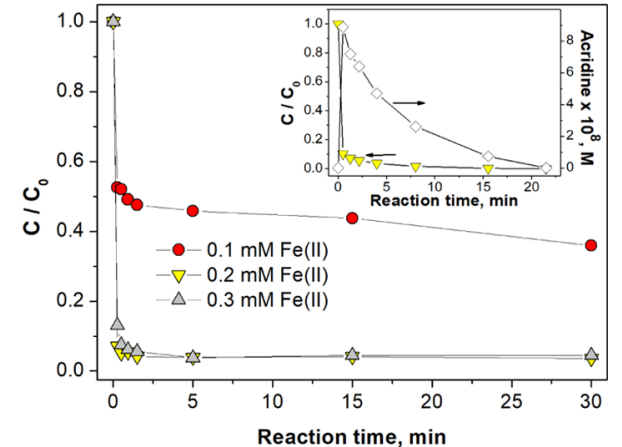

Figure 2. Time trend of $\mathrm{CBZ}$ (initial concentration $10 \mathrm{ppm}, \mathrm{pH} 3$ by $\mathrm{H}_{2} \mathrm{SO}_{4}$ ) under different Fenton conditions: (A) increasing concentration of $\mathrm{H}_{2} \mathrm{O}_{2}(1,2$, and $3 \mathrm{mM})$ with $[\mathrm{Fe}(\mathrm{II})]=0.1 \mathrm{mM}$; (B) increasing concentration of $\mathrm{Fe}(\mathrm{II})(0.1,0.2$, and $0.3 \mathrm{mM})$ with $\left[\mathrm{H}_{2} \mathrm{O}_{2}\right]=2 \mathrm{mM}$. Inset: Time trend of CBZ (triangles, left $Y$-axis) and acridine (diamonds, right $Y$-axis) under the following conditions: $C_{\mathrm{o}}(\mathrm{CBZ})=10 \mathrm{ppm}, \mathrm{pH} 3,[\mathrm{Fe}(\mathrm{II})]=0.2$ $\mathrm{mM},\left[\mathrm{H}_{2} \mathrm{O}_{2}\right]=2 \mathrm{mM}$.

minimize the uncertainty related to the determination of concentration values that are relatively near the highperformance liquid chromatography (HPLC) limit of detection. Moreover, the use of an elevated $C_{o}$ value would also stress the degradation ability of the investigated technology. Figure 2 shows the time trend of $10 \mathrm{ppm} \mathrm{CBZ}$ with increasing initial concentration values of hydrogen peroxide $(1,2,3 \mathrm{mM})$ at constant initial $[\mathrm{Fe}(\mathrm{II})]=0.1 \mathrm{mM}$ (Figure 2a), as well as with increasing $\mathrm{Fe}(\mathrm{II})(0.1,0.2,0.3$ $\mathrm{mM}$ ) at constant $\left[\mathrm{H}_{2} \mathrm{O}_{2}\right]=2 \mathrm{mM}$ (Figure $2 \mathrm{~b}$ ). The $\mathrm{pH}$ value of all the experiments was 3 by $\mathrm{H}_{2} \mathrm{SO}_{4}$, which is the optimum $\mathrm{pH}$ of the Fenton reaction. ${ }^{25}$ The choice of sulfuric acid was motivated by the facts that its counterion does not scavenge ' $\mathrm{OH}$ (differently from the case of $\mathrm{HCl}^{4}{ }^{47}$ Buxton et al., 1988) and it is nontoxic (unlike $\mathrm{HNO}_{3}$ and $\mathrm{HClO}_{4}$ ). As often observed for the thermal Fenton process, ${ }^{10}$ the degradation of CBZ was a two-step pathway made up of a fast initial step [the ferrous step, triggered by the reaction between $\mathrm{Fe}(\mathrm{II})$ and $\mathrm{H}_{2} \mathrm{O}_{2}$ ] lasting around 1 min or less, ${ }^{10}$ followed by a slower ferric step dominated by $\mathrm{Fe}$ (III) reduction. For this reason, for the fact that $\mathrm{Fe}^{2+}$ and $\mathrm{H}_{2} \mathrm{O}_{2}$ react in 1:1 ratio, as well as for the ability of $\mathrm{H}_{2} \mathrm{O}_{2}$ to scavenge ${ }^{\circ} \mathrm{OH}$, no complete $\mathrm{CBZ}$ degradation could be achieved with $0.1 \mathrm{mM} F e(\mathrm{II})$, even by increasing the $\mathrm{H}_{2} \mathrm{O}_{2}$ concentration. In contrast, by doubling the concentration of $\mathrm{Fe}$ (II) from 0.1 to $0.2 \mathrm{mM}$, we observed a complete CBZ removal in the first $5 \mathrm{~min}$ of the reaction (mostly carried out in the ferrous step, with some eventual contribution by the ferric one). Therefore, the degradation experiments that follow were carried out with $2 \mathrm{mM} \mathrm{H}_{2} \mathrm{O}_{2}$ and $0.2 \mathrm{mM} \mathrm{Fe}(\mathrm{II})$, always at $\mathrm{pH} 3$.

In the same conditions, an experiment was carried out to assess the possible production of acridine as the byproduct of CBZ transformation. Acridine is a mutagenic compound that has been observed as the byproduct of the photochemical transformation of CBZ in natural waters (see Figure 1-SI in the Supporting Information, hereafter SI, for a likely pathway of CBZ transformation into acridine). ${ }^{48}$ The monitoring of acridine is mandatory to understand if the transformation of CBZ can produce a more hazardous compound than the parent one in the studied Fenton conditions. The inset of Figure $2 \mathrm{~b}$ shows the time evolution of acridine, which was actually formed with a concentration peak $\left(9 \times 10^{-8} \mathrm{M}\right.$, i.e., $0.2 \%$ of the initial $4.2 \times 10^{-5} \mathrm{M} \mathrm{CBZ}$ ) that was reached in the first minute of the reaction, before a progressive decrease down to zero concentration. The observed time trend of acridine is of no concern from an environmental point of view because (i) the peak concentration was very low $(\approx 0.2 \%$ of the initial $\mathrm{CBZ}$ ) and (ii) acridine disappeared at reaction time $\geq 20 \mathrm{~min}$.

The Fenton degradation of $\mathrm{CBZ}$ was then investigated in the presence of three different organic macromolecules (HA, Alg, and BSA), to simulate the occurrence of structurally very different compounds that are able to scavenge the reactive transient species and that can be potentially removed by NF. Therefore, the $\mathrm{CBZ}\left(C_{\mathrm{o}}=10 \mathrm{ppm}\right)$ time trends were monitored in the presence of increasing concentrations of $\mathrm{HA}$ (from 5 to $120 \mathrm{ppm}$, Figure 3a), Alg (from 5 to $480 \mathrm{ppm}$, Figure $3 \mathrm{~b}$ ), and BSA (from 5 to $480 \mathrm{ppm}$, Figure 3c). In all the cases, one observes an inhibition of $\mathrm{CBZ}$ degradation as the concentration of the scavenger increases, most likely as a consequence of the increasing consumption of the reactive transient species (e.g., ${ }^{\bullet} \mathrm{OH}$ ) that are thus subtracted to the reaction with $\mathrm{CBZ}$.

The inhibition effect is strongly affected by the nature of the macromolecule employed ( $\mathrm{HA}>\mathrm{Alg}>\mathrm{BSA}$ ), as shown by the fact that the inhibition carried out by 120 ppm HA was definitely more marked compared to 480 ppm BSA or Alg (see Figure 3). The different extent of inhibition of CBZ degradation carried out by HA, BSA, and Alg can be accounted for by the structural properties of the three model interfering agents. Alg is a polysaccharide with mainly aliphatic (sugar) chains, which are known to react with ${ }^{\circ} \mathrm{OH}$ and similar oxidants but with relatively slow kinetics compared to other functional groups. ${ }^{47}$ Aliphatic (amino-acidic) groups would also prevail in the case of BSA that has only some aromatic amino acids (phenylalanine, tyrosine, and tryptophan) able to react fast with the oxidizing species. In contrast, HA has a large aromatic fraction that could warrant elevated reactivity with - ${ }^{4}{ }^{47}$

In a following experimental series, we tested the NF-Fenton performance in the presence of concentrations of scavengers that were shown in the above experiments to produce an important inhibition of CBZ degradation ( 80 ppm HA, 360 ppm Alg, and 240 ppm BSA). The NF-Fenton results were then compared with those obtained with Fenton alone, by carrying out the Fenton degradation experiments on asprepared solutions and on solutions after NF treatment. To achieve extensive CBZ degradation under all the tested conditions, in this series of experiments we made multiple 
A

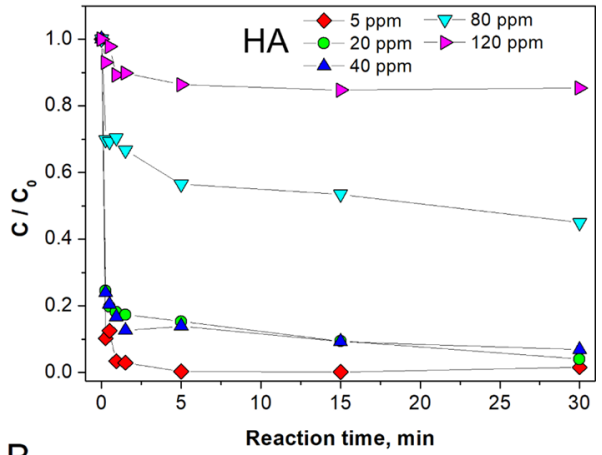

B

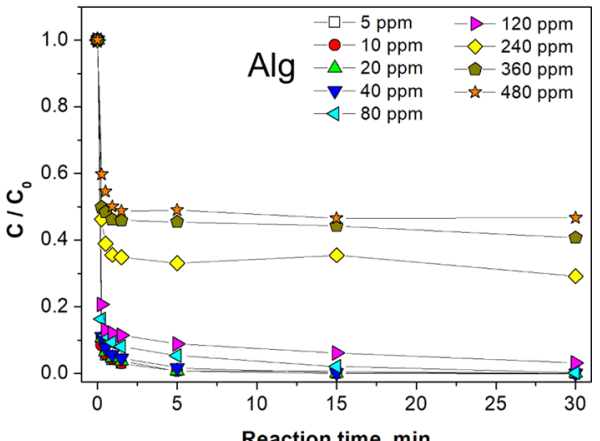

C

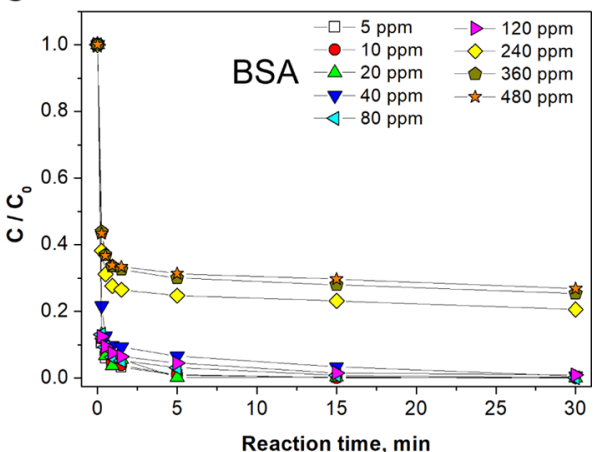

Figure 3. Time trend of $\mathrm{CBZ}\left[\mathrm{C}_{\mathrm{o}}=10 \mathrm{ppm}, \mathrm{pH} 3\right.$ by $\mathrm{H}_{2} \mathrm{SO}_{4}, \mathrm{H}_{2} \mathrm{O}_{2} 2$ $\mathrm{mM}, \mathrm{Fe}(\mathrm{II}) 0.2 \mathrm{mM}]$ in the presence of increasing amounts of $\mathrm{HA}$ (A), $\operatorname{Alg}(\mathrm{B})$, and BSA (C).

additions of the Fenton reagent and, particularly, one every 10 minutes. The advantage of making multiple Fenton additions over using a larger amount of reagents right at the beginning of the process is that by using each time lower concentration values of $\mathrm{Fe}(\mathrm{II})$ and $\mathrm{H}_{2} \mathrm{O}_{2}$, one minimizes the problems connected with ${ }^{\circ} \mathrm{OH}$ scavenging by the two reactants, which becomes more important as their concentrations get higher. ${ }^{49}$

Figure 4 shows the $\mathrm{CBZ}$ time-trend profile in the presence of HA (Figure 4a), Alg (Figure 4b), and BSA (Figure 4c). In all the cases, the NF-Fenton approach allowed for complete CBZ abatement (meaning that CBZ became undetectable by HPLC) after the second addition of the Fenton reagent. In contrast, the Fenton reaction alone without the NF pretreatment step required a third addition of the reactants, and even in this case a residual concentration of CBZ was observed at the end of the treatment. This finding is in agreement with (i) the large rejections of $\mathrm{HA}, \mathrm{Alg}$, and BSA carried out by NF (see Figure 1) and (ii) the important inhibition effect carried out by HA, Alg, and BSA on the Fenton degradation of CBZ. Therefore, as was expected, the preliminary NF elimination of
A

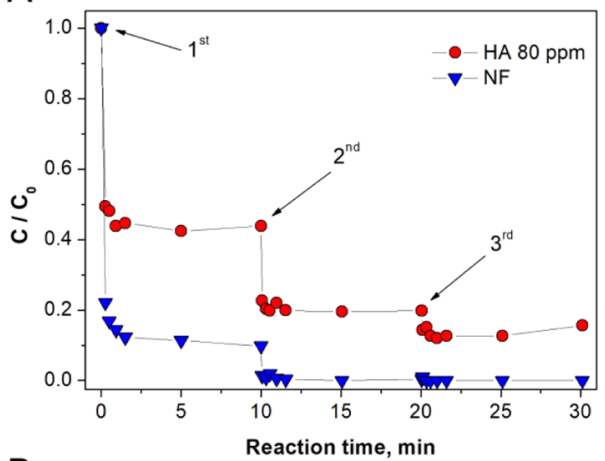

B

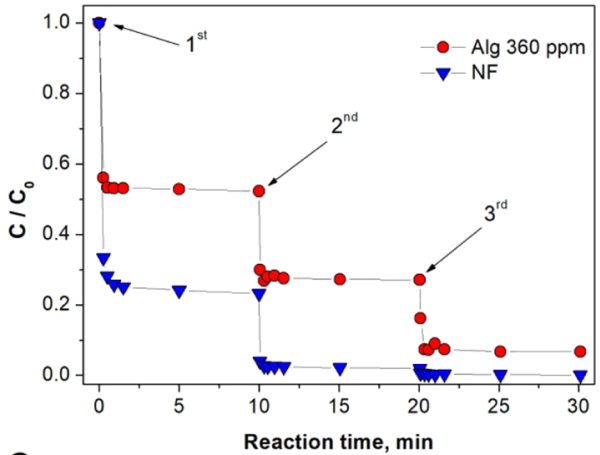

C

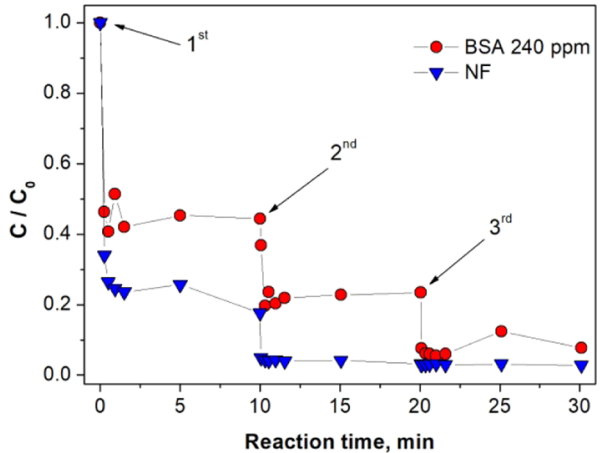

Figure 4. Time trend of CBZ $\left(C_{o}=10 \mathrm{ppm}\right)$ in three-step experiments ( $\mathrm{pH} 3$ by $\mathrm{H}_{2} \mathrm{SO}_{4}$ and, for each addition step, $\mathrm{H}_{2} \mathrm{O}_{2} 2 \mathrm{mM}$ + $\mathrm{Fe}(\mathrm{II}) 0.2 \mathrm{mM}$ ), in the presence of $\mathrm{HA} 80 \mathrm{ppm}$ (A), Alg $360 \mathrm{ppm}$ (B), and BSA $240 \mathrm{ppm}$ (C), observed on as-prepared solutions and after NF. First, second, and third indicate the time of each subsequent addition of the Fenton reagent.

the interfering agents proved to significantly favor the following oxidation step.

NF-Fenton Coupling To Achieve CBZ Degradation in Real WWTP samples. Once demonstrated that the NFFenton coupling can work well with synthetic solutions, we moved toward real samples obtained from a wastewater treatment facility. The aim was to investigate the behavior of wastewaters (whatever their origin, either urban or industrial) that are rich in potential scavengers of oxidizing species.

Negligible rejection of CBZ by NF was observed on real samples as well, which confirms that the functioning of our NF system was the same in both synthetic solutions and actual wastewater. Figure 5 shows the time trends of CBZ $\left(C_{\mathrm{o}}=10\right.$ $\mathrm{ppm}$ ) upon three subsequent additions of the Fenton reagent, carried out on the Primary sample (sampled at the exit of the primary clarifier, Figure 5a) and on the Secondary sample (obtained at the exit of the secondary clarifier, Figure $5 b$ ), 
A

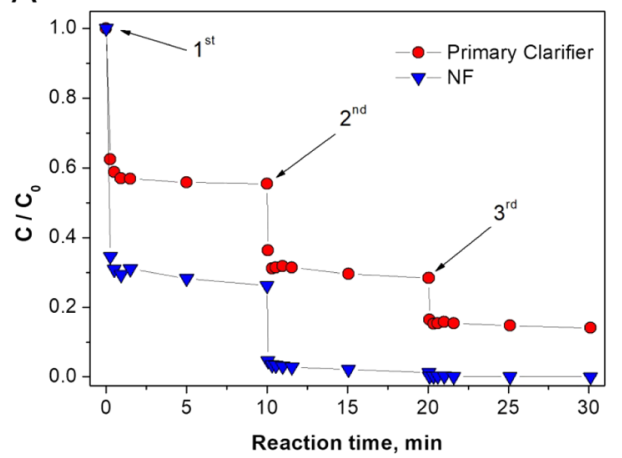

B

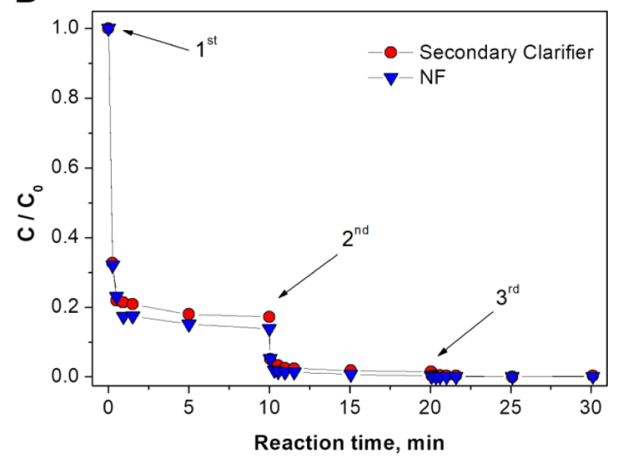

Figure 5. Time trend of $\mathrm{CBZ}\left(\mathrm{C}_{\mathrm{o}}=10 \mathrm{ppm}\right)$ in three-step experiments $\left(\mathrm{pH} 3\right.$ by $\mathrm{H}_{2} \mathrm{SO}_{4}$ and, for each addition step, $\mathrm{H}_{2} \mathrm{O}_{2} 2 \mathrm{mM}+\mathrm{Fe}(\mathrm{II}) 0.2$ $\mathrm{mM}$ ), on Primary sample water (A) and Secondary sample water (B), used both as is and after NF. First, second, and third indicate the time of each subsequent addition of the Fenton reagent.

Table 1. Chemical Composition of the Primary Sample, before (S1) and after NF (S1-NF $)^{a}$

\begin{tabular}{|c|c|c|c|c|c|c|c|c|}
\hline & TOC $\mathrm{mg}_{\mathrm{C}} \mathrm{L}^{-1}$ & IC $\mathrm{mg}_{\mathrm{C}} \mathrm{L}^{-1}$ & $\mathrm{pH}$ & $\sigma \mathrm{mS} \mathrm{cm}^{-1}$ & {$\left[\mathrm{Cl}^{-}\right] \mathrm{mM}$} & {$\left[\mathrm{NO}_{2}^{-}\right] \mathrm{mM}$} & {$\left[\mathrm{NO}_{3}^{-}\right] \mathrm{mM}$} & {$\left[\mathrm{PO}_{4}^{-3}\right] \mathrm{mM}$} \\
\hline S1 & 21.5 & 76.2 & 7.38 & 0.967 & 2.60 & 0.029 & 0.006 & 0.085 \\
\hline S1-NF & 1.9 & 8.7 & 6.93 & 0.138 & 0.53 & 0.005 & 0.003 & 0.002 \\
\hline$R \%$ & 91 & 89 & $\mathrm{n} / \mathrm{a}$ & 86 & 80 & 84 & 50 & 98 \\
\hline & {$\left[\mathrm{SO}_{4}{ }^{-2}\right] \mathrm{mM}$} & {$\left[\mathrm{Na}^{+}\right] \mathrm{mM}$} & {$\left[\mathrm{NH}_{4}{ }^{+}\right] \mathrm{mM}$} & {$\left[\mathrm{K}^{+}\right] \mathrm{mM}$} & {$\left[\mathrm{Mg}^{+2}\right] \mathrm{mM}$} & {$\left[\mathrm{Ca}^{+2}\right] \mathrm{mM}$} & $\mathrm{TN} \mathrm{mg}_{\mathrm{N}} \mathrm{L}^{-1}$ & TON $\mathrm{mg}_{\mathrm{N}} \mathrm{L}^{-1}$ \\
\hline S1 & 1.19 & 4.13 & 1.67 & 0.55 & 0.516 & 0.959 & 31.38 & 7.47 \\
\hline S1-NF & 0.03 & 0.61 & 0.47 & 0.39 & 0.033 & 0.029 & 7.28 & 0.64 \\
\hline
\end{tabular}

${ }^{a_{\mathrm{TOC}}}=$ total organic carbon, $\mathrm{IC}=$ inorganic carbon, $\sigma=$ conductivity, $\mathrm{TN}=$ total nitrogen, $\mathrm{TON}=$ total organic nitrogen, $R \%=$ loose $\mathrm{NF}$ rejection \%. n/a: not applicable.

A

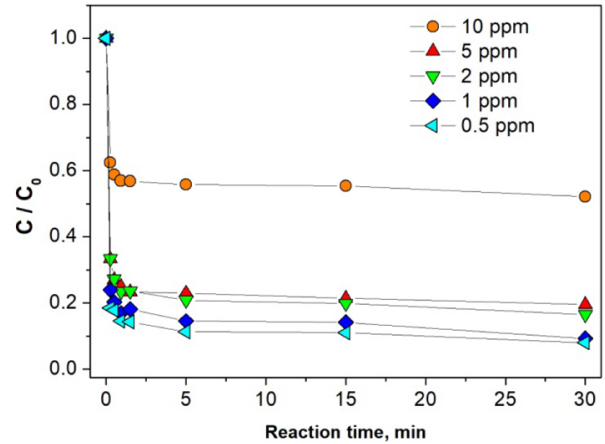

B

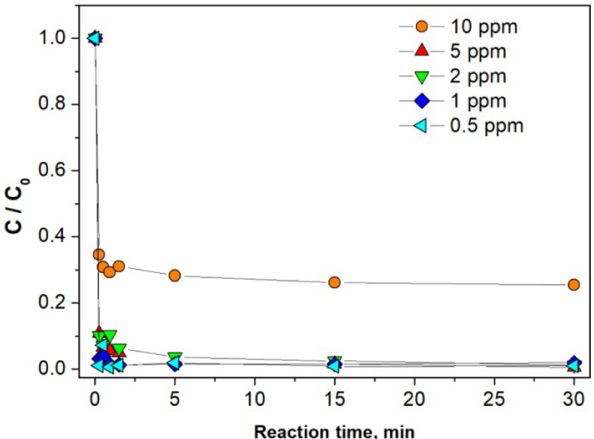

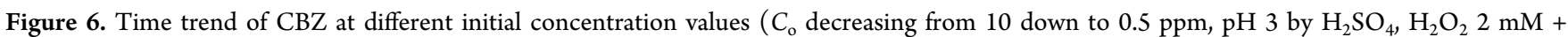
$\mathrm{Fe}$ (II) $0.2 \mathrm{mM}$ for each addition step) in the Primary sample water used as is (A) or after NF (B).

following both the NF-Fenton and the Fenton-alone approaches. The results observed on the Primary sample are very similar to those already reported in Figure 4 for the synthetic interfering agents. Indeed, the NF pretreatment step allowed for a considerable saving in the use of the Fenton reagent to degrade $\mathrm{CBZ}$. In the NF-Fenton case, the $\mathrm{CBZ}$ was in fact completely removed after the second addition of Fenton, whereas after the third addition of Fenton, a significant amount of residual CBZ $(\sim 2 \mathrm{ppm})$ in the Fenton-only treatment was observed.

Interestingly, the preliminary NF step was able to remove $\sim 91 \%$ of the organic material occurring in the Primary sample (having TOC $=21.5 \mathrm{mg}_{\mathrm{C}} \mathrm{L}^{-1}$ before NF), thereby confirming the ability of loose NF to remove the scavengers of the reactive species that occur in wastewater. In contrast, the NF-Fenton performance was fully comparable with that of Fenton alone with the Secondary sample, where in both cases the second addition of Fenton reactants allowed for complete CBZ removal (see Figure $5 b$ ). The most likely explanation for this finding resides in the much lower TOC value of the Secondary sample $\left(1.9 \mathrm{mg}_{\mathrm{C}} \mathrm{L}^{-1}\right)$ as compared to the Primary sample (21.5 $\left.\mathrm{mg}_{\mathrm{C}} \mathrm{L}^{-1}\right)$.

Therefore, in the case of the Secondary sample, there is no real need of a preliminary NF step to eliminate interfering organic compounds. For this reason, the following tests were carried out on the Primary sample alone. Interestingly, the NF step allowed for a significant overall improvement of the water quality of the Primary sample, referred not only to the TOC abatement but also to the decrease of the concentration values of the main anions and cations (and of the conductivity as a consequence), as well as of total nitrogen (TN) and total organic nitrogen (TON). Table 1 shows the comparison between the main chemical parameters for the Primary Sample, before $(\mathrm{S} 1)$ and after $(\mathrm{S} 1-\mathrm{NF})$ the NF treatment step. 
At the explored reaction times, only the ferrous step of the Fenton process was operational, which accounts for the steplike feature of CBZ time evolution (Figure 5) and makes the $\mathrm{Fe}(\mathrm{II})$ salt a reagent more than a catalyst. In real applications, one needs the tertiary treatment to work quickly, and the fast ferrous step allowed for keeping treatment times below 10 min per addition. This is compatible with the time requirements in the treatment of high flows of wastewater, while there would hardly be time to wait that the slower ferric step contributes to CBZ degradation.

So far, the experiments were carried out with a rather high CBZ concentration that required the use of high amounts of Fenton reagents. To execute experiments that are more representative of a real-world scenario, we gradually lowered the concentration of CBZ spiked to the Primary sample water, from the original 10 to $0.5 \mathrm{ppm}$ (i.e., from 42 to $2 \mu \mathrm{M}$ ). The comparison between NF-Fenton (Figure 6a) and Fenton alone (Figure $6 \mathrm{~b}$ ) under low-concentration conditions suggests that NF-Fenton still allows for more efficient CBZ removal compared to Fenton alone.

If the initial CBZ concentration is decreased, it makes sense to decrease as well the amounts of $\mathrm{Fe}$ (II) and $\mathrm{H}_{2} \mathrm{O}_{2}$ that are needed for the degradation, to avoid operating with excessively high-concentration values that would negatively affect the process costs. Therefore, several tests were carried out by progressively lowering the concentration of both $\mathrm{Fe}$ (II) and $\mathrm{H}_{2} \mathrm{O}_{2}$ in the context of the NF-Fenton treatment (see Figure 7 for the observed CBZ time trends). The use of $0.5 \mathrm{mM} \mathrm{H}_{2} \mathrm{O}_{2}$

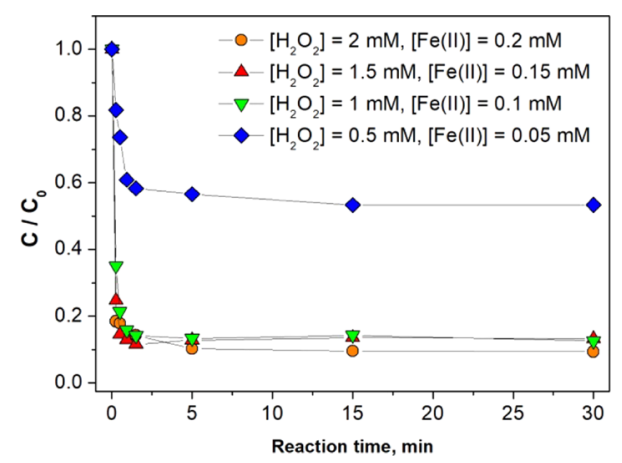

Figure 7. Time trend of $\mathrm{CBZ}\left(\mathrm{C}_{\mathrm{o}}=0.5 \mathrm{ppm}, \mathrm{pH} 3\right.$ by $\left.\mathrm{H}_{2} \mathrm{SO}_{4}\right)$ in water sampled after a primary sedimentation tank (Primary sample), with different concentrations of the Fenton reagent.

+ $0.05 \mathrm{mM} \mathrm{Fe}$ (II) allowed for the CBZ concentration to be halved from the initial $0.5 \mathrm{ppm}$, and this result looks reasonable in the context of multiple Fenton additions to limit the scavenging ability of both reactants. Therefore, the final comparison between NF-Fenton and Fenton alone was carried out in the presence of $\mathrm{CBZ}\left(C_{\mathrm{o}}=0.5 \mathrm{ppm}\right)$ at $\mathrm{pH} 3$, with consecutive additions of $\mathrm{Fe}(\mathrm{II})$ and $\mathrm{H}_{2} \mathrm{O}_{2}$. The added amounts were such that after the first addition, one had 0.5 $\mathrm{mM} \mathrm{H} \mathrm{H}_{2} \mathrm{O}_{2}$ and $0.05 \mathrm{mM} \mathrm{Fe}$ (II).

As shown in Figure 8, for Fenton alone one had still 10\% of the initial CBZ after the fifth addition, whereas in the case of $\mathrm{NF}-$ Fenton, the same result could be obtained with only two additions. This difference between the performances of Fenton and NF-Fenton toward the Primary sample water was considered for the following economic analysis of the treatment performance. Note that each degradation was carried out in duplicate, with very good reproducibility.

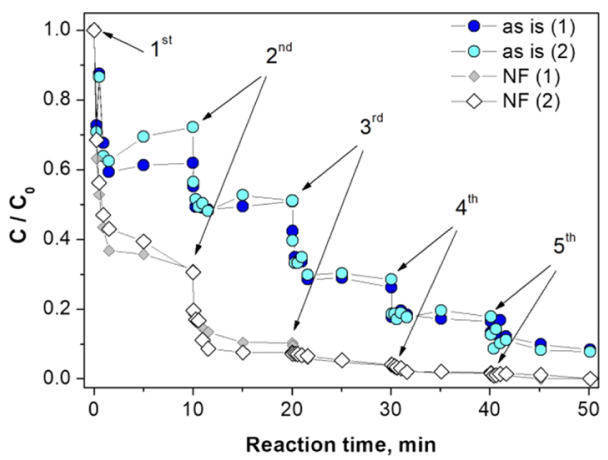

Figure 8. Time trend of $\mathrm{CBZ}$ in five-step experiments, shown in duplicates $\left(\mathrm{C}_{\mathrm{o}}=0.5 \mathrm{ppm}\right.$, $\mathrm{pH} 3$ by $\mathrm{H}_{2} \mathrm{SO}_{4}, \mathrm{H}_{2} \mathrm{O}_{2} 0.5 \mathrm{mM}+\mathrm{Fe}(\mathrm{II})$ $0.05 \mathrm{mM}$ for each addition step), in water sampled after the primary sedimentation tank, used as is or previously subjected to NF. First, second, third, fourth, and fifth indicate the time of each subsequent addition of the Fenton reagent.

Cost Analysis. A comparison of costs associated with Fenton-based oxidation alone or following pretreatment by NF was performed to assess the feasibility of the proposed system. The present estimate is based on the treatment of a unit flow rate of wastewater $\left(1 \mathrm{~m}^{3} \mathrm{~h}^{-1}\right)$, having similar characteristics as the Primary sample used in this study. Note that even if the cost analysis is strongly related to the type of water to be treated and its output can change abruptly as a function of its composition (e.g., the buffer capacity and/or the nature of the organic scavengers), the methodology used here is of general validity and can be applied to different kinds of wastewaters.

The target CBZ degradation was $90 \%$ of the initial concentration, thereby leaving $10 \%$ residual CBZ after the treatment. As shown above, this abatement value was achieved upon five additions of reagents when the primary effluent was treated with Fenton alone and upon two additions in the case of NF-Fenton (Figure 8). The wholesale cost of reagents was assumed, and in particular, 240,100, 500, and $120 \$$ ton $^{-1}$ for, respectively, $\mathrm{H}_{2} \mathrm{SO}_{4}$ ( $96 \%$ purity), $\mathrm{FeSO}_{4} \cdot 7 \mathrm{H}_{2} \mathrm{O}, \mathrm{H}_{2} \mathrm{O}_{2}(50 \%$ solution in water), and $\mathrm{CaO}$ (needed to neutralize the solution after Fenton oxidation). The membrane chosen for the estimation of the capital and operational costs of the system was the HydraCoRe70pHT 8040-46. On the basis of the results of Figure 1, the flux of wastewater per unit applied pressure was assumed to be $1.3 \mathrm{LMH} \mathrm{bar}{ }^{-1}$, the recovery rate was chosen as $70 \%$ ( $70 \%$ of the stream recovered in the highquality permeate and $30 \%$ in the concentrated retentate stream), and the applied pressure was 10 bar.

The operational cost of the Fenton oxidation process applied directly downstream of the primary clarifier is $\$ 0.20$ for each $\mathrm{m}^{3}$ of the treated water (see Figure $9 \mathrm{~b}$ for the relevant treatment train and Table 1-SI for the detailed cost analysis). The largest contributions to total costs derive from the addition of sulfuric acid and hydrogen peroxide, accounting each for $40 \%$ of the total reagent costs. Disposal of the neutralized effluent from this step, containing high levels of organic material and iron, would cost an additional $0.38 \$ \mathrm{~m}^{-3}$ based on the current price of wastewater disposal in Italy. ${ }^{50}$ That yields a total cost of $0.58 \$ \mathrm{~m}^{-3}$ when Fenton oxidation is applied directly downstream of the primary clarifier. Interestingly, if one wants to upgrade a WWTP for CBZ abatement by using the Fenton reaction after the primary effluent, the operational costs would be increased by $\sim 50 \%$ that is a significant price increase but not unsustainable, in particular, in 

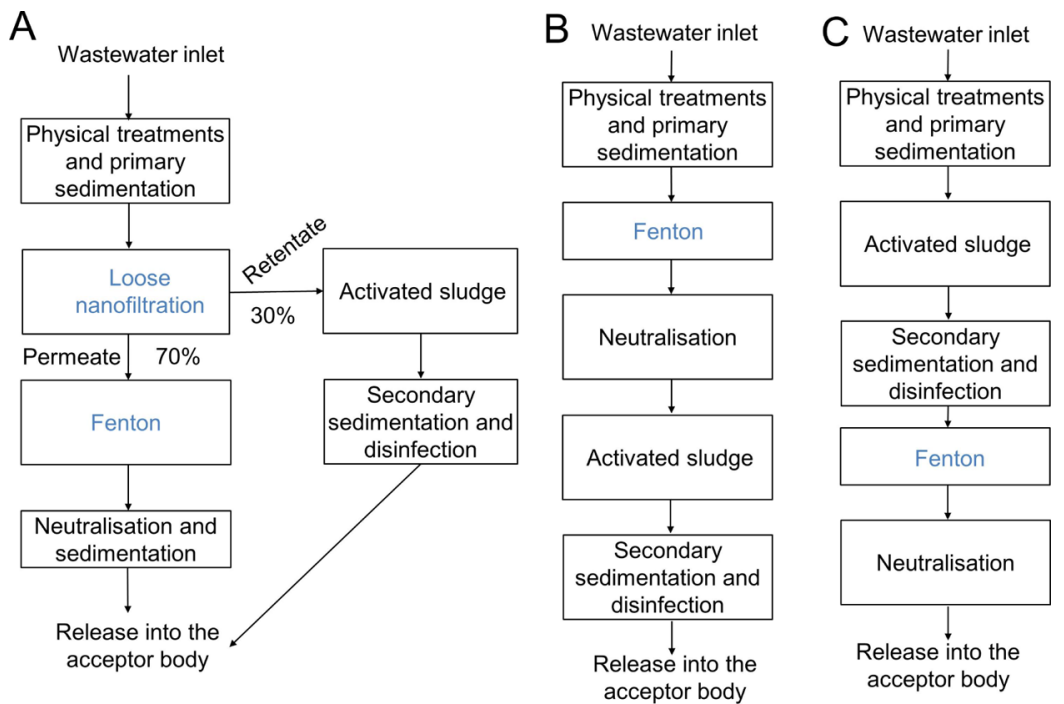

Figure 9. Schematic of the hypothetical treatment trains assumed for the assessment of treatment costs, with (A) or without (B,C) NF.

the framework of future legislation (and current one in Switzerland, for instance ${ }^{51,52}$ ) that will enforce the elimination of emerging contaminants from wastewater.

On the contrary, if the Fenton reaction is conducted with the purified permeate stream coming from the NF step (see Figure 9a and Table 1-SI), the reagent costs are reduced to $0.05 \$ \mathrm{~m}^{-3}$ (where the volume is referred to the total feed water). It can be safely assumed that the amounts of organic material and iron (after a sedimentation step) present in this effluent are low enough to allow safe discharge into the receiving water body. Compared to Fenton oxidation directly downstream of the primary clarifier, the NF pretreatment allows for saving $>75 \%$ of the Fenton costs. The reason is not only the lower (roughly halved) amount of the Fenton reagent needed to carry out the oxidation but also the lower buffer capacity of the permeate stream compared to the feed wastewater, caused by the extensive removal of inorganic ions and organic carbon. The lower buffer capacity does in fact entail a very significant decrease of the amounts of $\mathrm{H}_{2} \mathrm{SO}_{4}$ and $\mathrm{CaO}$ that are required to adjust $\mathrm{pH}$ before and after the Fenton process.

If the Fenton process were to be applied directly to the effluent of the secondary clarifier in scenario $\mathrm{C}$, the target abatement value would be reached with two additions of reagents (see Figure $5 b$ ). This can be ascribed to the reduction in organic matter operated by the extensive treatment prior to the oxidation step. The target CBZ abatement value (90\%) would require a total reagent cost of $0.07 \$ \mathrm{~m}^{-3}$, including $\mathrm{pH}$ neutralization, equivalent to roughly $130 \%$ of the reagent cost in the case of Fenton oxidation occurring downstream of the NF pretreatment of the primary effluent in scenario A. The effluent from the Fenton process in scenario $\mathrm{C}$ may be safely discharged to the receiving water body.

One should not forget that a membrane plant has significant installation and operational costs that should be taken into account in the present assessment. On the basis of the assumptions mentioned above, the treatment of $1 \mathrm{~m}^{3} \mathrm{~h}^{-1}$ of wastewater requires $75 \mathrm{~m}^{2}$ of the active membrane. The installation costs of the membrane plant per unit membrane area reported in the literature are $400 \$ \mathrm{~m}^{-2}$ for sufficiently large plants $\left(>500 \mathrm{~m}^{2}\right.$ of total membrane area), yielding a total installation cost of roughly $\$ 30000$ to treat the unit flow rate. ${ }^{53}$ Operational costs of the membrane system include the following: (i) membrane replacement costs (replacement of the membrane every 3 years leads to an extra cost ${ }^{54}$ of approximately $0.02 \$ \mathrm{~m}^{-3}$ ); (ii) energy-associated costs: for a pumping system with $70 \%$ efficiency and including energy recovery, and for a cost of energy of $0.19 \$ \mathrm{~kW} \mathrm{~h}^{-1}$, the specific costs to drive the separation ${ }^{55}$ are roughly $0.04 \$ \mathrm{~m}^{-3}$; (iii) costs for the disposal of the concentrate stream (flow of $0.3 \mathrm{~m}^{3}$ $\mathrm{h}^{-1}$, namely, $30 \%$ of the unit flow rate of wastewater), at $0.11 \$$ per each $\mathrm{m}^{3}$ volume of the feed wastewater stream (i.e., $30 \%$ of the $0.38 \$ \mathrm{~m}^{-3}$ cost for wastewater disposal), and (iv) chemical reagents for membrane cleaning (roughly $0.01 \$ \mathrm{~m}^{-3}$ ). ${ }^{54}$ As such, the total operational cost of the system made up of NF followed by the Fenton reaction is estimated to be approximately $0.23 \$ \mathrm{~m}^{-3}$. Therefore, total operational savings would be $\$ 0.35$ for each $\mathrm{m}^{3}$ of feed water (i.e., $0.23 \$ \mathrm{~m}^{-3}$ against $0.58 \$ \mathrm{~m}^{-3}$ ), compared to a treatment train that includes a Fenton-based step without NF. Therefore, the installation of a membrane system is justified if the plant is to be operated for 10 years or longer.

Our estimations did not consider the cost of the necessary sedimentation to separate the solids produced during the neutralization step after the Fenton reaction, whose amount is roughly proportional to that of the reagents used and would thus be much higher in the scenario without NF pretreatment.

In case B of Figure 9, the problem of iron is not so significant because the effluent, once neutralized after the Fenton reactor, enters in the active sludge plant and the iron is blocked within the sludge and then treated in the sludge line. In the other two cases (A and $\mathrm{C}$ ), one needs to install a further clarifier, but the sedimentation of iron at neutral $\mathrm{pH}$ is not a technological challenge (the use of iron colloids is a common strategy to promote the sedimentation of fine particles). Furthermore, in a circular economy context, the opportunity to recycle the iron-rich sludge as the raw material for certain industries (e.g., companies producing pigments) could be considered.

Also, one of the factors tipping the balance in favor of the membrane-based process is the availability of space. The present estimates did in fact not consider the clear advantage in the footprint of installing a modular and compact membrane 
system compared to larger Fenton reactors, larger biological tanks, and/or the necessary secondary clarifiers.

\section{CONCLUSIONS}

- When applied to a water matrix that was rich in the scavengers of the reactive species, NF-Fenton performed significantly better than Fenton alone in micropollutant (CBZ) degradation. The reason is largely due to the NF ability to selectively remove scavengers (HA, Alg, and BSA in synthetic solutions; TOC, ions, TN and TON in actual wastewater), thereby facilitating the Fenton reaction. In contrast, the coupling of Fenton with NF seems much less justified when operating on matrices that contain fewer interfering agents.

- The cost savings allowed by NF-Fenton compared to Fenton alone are due to both lower levels of reactants (especially $\mathrm{H}_{2} \mathrm{O}_{2}$ ) needed to degrade $\mathrm{CBZ}$ and (unexpectedly, even more than that) to lower amounts of acids and bases required for $\mathrm{pH}$ adjustment before and after the Fenton treatment.

- The NF-Fenton approach can be applied to the treatment of wastewaters characterized at the same time by high concentrations of biodegradable agents and of biorecalcitrant micropollutants. In this case, the wastewater effluent would be split by NF into two fractions, that is, a NF retentate that is rich in biodegradable macropollutants but has no micropollutants and a permeate that is poor in interfering species but contains the micropollutants. These fractions can be treated through two different processes (activated sludge vs Fenton, respectively), thereby substantially enhancing the overall quality of the treated wastewater in terms of both micro- and macropollutants. The treated water has sufficiently high quality to enable its reuse in other human activities, which might be interesting in a framework of water scarcity.

- Because the use of NF-Fenton is only justified in the presence of high concentrations of the interfering species, one needs an in-depth evaluation of the change of the NF permeation ability at long working times (higher than those tested here), for example, to properly assess the role of fouling on the overall features of the NF membrane. Fouling could be very significant with urban wastewater having an elevated bacterial load, but it could be less problematic with industrial wastewater.

\section{EXPERIMENTAL SECTION}

Materials and Methods. All the compounds employed in this work were of analytical grade, and they were used without any further purification step. Water used was of Milli-Q quality (TOC $<2 \mathrm{ppb}$, resistivity $\geq 18 \mathrm{M} \Omega \mathrm{cm}$ ). The reagents acetonitrile (gradient grade), methanol (gradient grade), $\mathrm{H}_{3} \mathrm{PO}_{4}(85 \mathrm{w} / \mathrm{w} \%)$, BSA $(\geq 96 \%), \mathrm{CBZ}(\geq 98 \%), \mathrm{NaOH}$ ( $\geq 99 \%), \mathrm{H}_{2} \mathrm{O}_{2}(30 \mathrm{w} / \mathrm{w} \%$ in water), HA sodium salt (technical grade), and Alg were purchased from Sigma-Aldrich; $\mathrm{H}_{2} \mathrm{SO}_{4}(95-97 \%)$ and $\mathrm{FeSO}_{4} \times 7 \mathrm{H}_{2} \mathrm{O}(\geq 99.5 \%)$ were from Merck.

Real Wastewater Samples. The real wastewater samples were provided by SMAT S.p.A. (Società Metropolitana Acque Torino, Italy) and were sampled at the wastewater treatment facility of Castiglione Torinese (Italy) on 3 November 2017. The WWTP of Castiglione Torinese is one of the largest such facilities in Italy, and it provides wastewater treatment services for a potential population equivalent of 3.9 million inhabitants. In this plant, the wastewater stream undergoes the common treatment steps usually implemented in urban WWTPs: after the physical treatments (coarse-and-fine materials separation, grit removal, deodorization, and oil and grease removal) that eliminate most suspended solids and approximately one-third of the original organic carbon, the flow enters into a primary clarifier tank after which the water is subjected to denitrification and to a biological oxidative step before the secondary sedimentation. The water outflowing the secondary clarifier tank is eventually disinfected and released into the acceptor body (the River Po). The samples used in this work were obtained from the outflow of the primary clarifier tank (Primary sample) and of the secondary clarifier tank (Secondary sample). Real samples were used after a rough prefiltration step, carried out through a grade 1 qualitative filter paper (Whatman) to remove large suspended solids.

Membrane. The membrane used in the experiments was HydraCoRe70 (abbreviated as Hydra70) purchased from Hydranautics, Nitto Denko Group. This membrane consists of a thin separation layer made of highly negatively charged sulfonated polyethersulfone. This layer is chemically stable at $\mathrm{pH} 2-13$, and it rejects salts in the order $\mathrm{Na}_{2} \mathrm{SO}_{4}>\mathrm{NaCl}>$ $\mathrm{MgSO}_{4}>\mathrm{MgCl}_{2}>\mathrm{CaCl}_{2}$, as certified by the manufacturer. Our experiments showed a water permeance of 4.0 LMH $\mathrm{bar}^{-1}$ ) and an observed rejection of roughly $80 \%$ for $\mathrm{NaCl}$ and $\mathrm{MgSO}_{4}$, when the feed solution contained $30 \mathrm{mM}$ of each single salt at $\mathrm{pH}$ 7.6. The solute separation capability of Hydra70 is provided by a combination of size exclusion and charge exclusion governed by the Donnan effect. This membrane may thus be described as a loose NF membrane, and it is usually applied in processes such as industrial or urban wastewater treatment, as well as surface- or well-water purification.

Membrane Filtration System. All separation experiments were performed using a cross-flow lab-scale unit. The unit comprises a high-pressure pump (Hydra-cell pump, Wanner Engineering, Inc., Minneapolis, MN), a membrane housing cell, a recirculating chiller for temperature control (model MC 1200, Lauda) connected to a stainless steel coil immersed in the feed tank, and a data acquisition system. The housing cell consists of a $7.9 \mathrm{~cm}$ long, $2.9 \mathrm{~cm}$ wide, and $0.3 \mathrm{~cm}$ high rectangular channel. The active area of the membrane sample is thus $23 \mathrm{~cm}^{2}$. The cross-flow rate was monitored by a floating disk rotameter and adjusted, along with the operating pressure, by means of a bypass valve and a back-pressure regulator (Swagelok, Solon, OH). The permeate flow rate was continuously measured throughout the experiments using an in-line flow sensor (Sensirion, Switzerland). The permeate and the retentate streams were recirculated back to the feed reservoir, and samples were collected from the recirculation lines.

Membrane Filtration Tests. Tests Using Synthetic Feed Solutions. Tests were performed after $5 \mathrm{~h}$ of membrane compaction at 300 psi $(20.7$ bar $)$ with ultrapure water as the feed solution. The cross-flow rate was set at $4.5 \mathrm{~L} \mathrm{~min}^{-1}$ (crossflow velocity of $0.85 \mathrm{~m} \mathrm{~s}^{-1}$ ) and the temperature of the feed solution at $22{ }^{\circ} \mathrm{C}$. Each test started by adjusting the operating pressure at $100 \mathrm{psi}(6.9 \mathrm{bar})$. At the steady state, the permeate flow values were measured for about $20 \mathrm{~min}$ to calculate pure water permeance. It followed the addition of solutes, organic substances, and/or CBZ to the feed solution, to obtain the 
desired feed mixture. Except for the tests performed to evaluate the influence of the ionic strength, the feed solutions contained a mixture of salts including $0.45 \mathrm{mM} \mathrm{KH}_{2} \mathrm{PO}_{4}, 9.20 \mathrm{mM} \mathrm{NaCl}$, $0.61 \mathrm{mM} \mathrm{MgSO}_{4}, 0.5 \mathrm{NaHCO}_{3}, 0.5 \mathrm{mM} \mathrm{CaCl}_{2}$, and $0.935 \mathrm{mM}$ $\mathrm{NH}_{4} \mathrm{Cl}$, thus yielding a total ionic strength of $14.7 \mathrm{mM}$ (Visual MINTEQ 3.0). Except for tests conducted to assess the influence of $\mathrm{pH}$, the $\mathrm{pH}$ of the feed solution was fixed at a value of 7.4. The $\mathrm{pH}$ was adjusted by the addition of small amounts of $\mathrm{H}_{2} \mathrm{SO}_{4}$ or $\mathrm{NaOH}$. When applicable, one type of organic macromolecule for each separate experiment, that is, $\mathrm{HA}$, Alg, or BSA, was added to the feed solution to reach a concentration of 80,360 , or $240 \mathrm{mg} \mathrm{L}^{-1}$, respectively. These concentrations were chosen based on preliminary inhibition tests performed on the Fenton degradation of CBZ. The concentration of CBZ in the feed solution was $10 \mathrm{mg} \mathrm{L}^{-1}$. Each change in the composition of the feed solution was followed by a $45 \mathrm{~min}$ step aimed at ensuring that a new steady state was reached, before sampling the permeate and the concentrate streams for further analyses, for degradation tests, and to measure TOC and CBZ rejection.

Tests Using Effluent Wastewater. Filtrations were run at an applied pressure of 300 psi (20.7 bar). Two types of filtration runs were conducted: (i) filtration of a sample as is and (ii) filtration of a sample with the addition of $10 \mathrm{mg} \mathrm{L}^{-1} \mathrm{CBZ}$. The permeate flux was monitored throughout the experiment to assess the decline because of membrane compaction and possible fouling. Concentrate and permeate samples were collected starting from the second hour and used for further degradation experiments, as well as to measure TOC and CBZ rejection.

Thermal Fenton Degradation Tests. For the synthetic water samples, CBZ solutions to be subjected to the thermal Fenton reaction were prepared at the desired concentration of $\mathrm{Fe}(\mathrm{II})$ (added as $\mathrm{FeSO}_{4} \times 7 \mathrm{H}_{2} \mathrm{O}$ ), $\mathrm{pH}$ (adjusted by $\mathrm{H}_{2} \mathrm{SO}_{4}$ ) and, if applicable, added with different concentrations of reactive species scavengers ( $\mathrm{HA}, \mathrm{BSA}$, and $\mathrm{Alg}$ ). In the experiments on effluent samples, the desired amount of $\mathrm{CBZ}$ was spiked to the sample to obtain the desired concentration.

Samples (total volume $50 \mathrm{~mL}$ ) were mechanically stirred in an air-open beaker during the reaction, which started when $\mathrm{H}_{2} \mathrm{O}_{2}$ was added to the sample (reaction time $t_{\mathrm{r}}=0$ ). At selected time intervals, precisely measured $0.5 \mathrm{~mL}$ aliquots were withdrawn from the reaction system and diluted with 0.5 $\mathrm{mL}$ methanol to quench the Fenton reaction. Afterward, the diluted solutions underwent HPLC analysis. Some degradation tests were carried out through multiple additions of the same amount of the Fenton reagent every $10 \mathrm{~min}$, with the aim of reaching complete $\mathrm{CBZ}$ degradation.

Analytical Determinations. The solutions of $\mathrm{CBZ}$ were always produced from saturated stock solutions prepared in ultrapure water. The concentration of the stock was checked daily by spectrophotometry at $285 \mathrm{~nm}$, using a UV/vis SPECORD S 600 instrument equipped with $1 \mathrm{~cm}$ cuvettes (Suprasil Quartz, Hellma). The CBZ time trends were monitored with an YL HPLC system 9300, equipped with an YL9330 Column Compartment, an YL9150 autosampler, and a spectrophotometric single-wavelength detector set at 200 $\mathrm{nm}$. The chromatographic separations were carried out with a RP-C18 LiChroCART-LiChrospher cartridge $(250 \mathrm{~mm} \times 4$ $\mathrm{mm}$, particle size $5 \mu \mathrm{m})$ in isocratic mode $\left(70 \% \mathrm{H}_{3} \mathrm{PO}_{4}\right.$ in water at $\mathrm{pH} 2.8,30 \%$ acetonitrile, total flow rate $\left.1 \mathrm{~mL} \mathrm{~min}^{-1}\right)$. In these conditions, the $\mathrm{CBZ}$ retention time was $7.8 \mathrm{~min}$, with a column dead time of $0.7 \mathrm{~min}$. Mutagenic acridine is by far the most problematic of the transformation intermediates arising from the oxidation of CBZ. ${ }^{48}$ The determination of acridine as the byproduct of the Fenton transformation of CBZ was carried out with the same chromatographic system, but by using as eluents $\mathrm{MeOH}(\mathrm{A})$ and phosphate buffer $10 \mathrm{mM}$ at $\mathrm{pH} 7.3$ (B). The elution was carried out at $\mathrm{A} / \mathrm{B}=50: 50$ for the first $8 \mathrm{~min}$, and then the conditions changed in $1 \mathrm{~min}$ to $\mathrm{A} / \mathrm{B}=$ 60:40 and stayed stable up to $20 \mathrm{~min}$ (retention time for acridine $16.9 \mathrm{~min}$ ).

TOC and TN were measured with a Shimadzu ON-LINE TOC-VCSH instrument, equipped with an ASI-V autosampler and fed with zero-grade air (Gruppo Sapio, Italy). The TOC concentration was obtained as the difference between the total carbon (TC) and the inorganic carbon (IC). The TN determination was based on the quantitative catalytic conversion of the inorganic and organic nitrogen into nitrogen oxide (NO), quantified with a chemiluminescence detector. The calibrations were carried out with previously dehydrated primary standards: $\mathrm{K}_{2} \mathrm{CO}_{3}$ for IC, potassium hydrogen phthalate for $\mathrm{TC}$, and $\mathrm{KNO}_{3}$ for $\mathrm{TN}$.

The retention ability of the membrane was also evaluated for the main cations and anions in the real Primary sample. Anions $\left(\mathrm{Cl}^{-}, \mathrm{NO}_{2}{ }^{-}, \mathrm{NO}_{3}{ }^{-}, \mathrm{SO}_{4}{ }^{2-}, \mathrm{PO}_{4}{ }^{3-}\right)$ and cations $\left(\mathrm{Na}^{+}, \mathrm{NH}_{4}^{+}\right.$, $\left.\mathrm{K}^{+}, \mathrm{Ca}^{2+}, \mathrm{Mg}^{2+}\right)$ were determined with a Dionex DX 500 ion chromatograph equipped with a gradient pump GP40, an electrochemical suppression unit (ASRS 300 for anions and CERS 500 for cations), an ED40 detector, and a Rheodyne injector (100 $\mu \mathrm{L}$ injection loop). The separation columns used were Dionex Ion Pac AS9-HC with an AG9-HC guard column for the anions and Dionex CS12A with a CG12A guard column for the cations. The used eluents were $9 \mathrm{mM} \mathrm{K} \mathrm{KO}_{3}$ (anions) and $20 \mathrm{mM}$ methanesulfonic acid (cations). In both cases, the total flow rate was $1 \mathrm{~mL} \mathrm{~min}{ }^{-1}$. The $\mathrm{pH}$ and the conductivity of the solutions were measured, respectively, with a Multi 340i pH meter (WTW Measurement Systems Inc.) and with a Microcomputer Conductivity meter model 131 (Analytical Control).

\section{ASSOCIATED CONTENT}

\section{S Supporting Information}

The Supporting Information is available free of charge on the ACS Publications website at DOI: 10.1021/acsomega.8b01055.

Transformation process of $\mathrm{CBZ}$ into acridine by ${ }^{\bullet} \mathrm{OH}$ and detailed cost analysis of the Fenton treatment as is or coupled with membrane pretreatment (PDF)

\section{AUTHOR INFORMATION}

\section{Corresponding Authors}

*E-mail: alberto.tiraferri@polito.it. Fax: +39-011-0907628. (A.T.).

*E-mail: davide.vione@unito.it. Fax: +39-011-6705242. Web: http://www.environmentalchemistry.unito.it (D.V.).

\section{ORCID}

Marco Minella: 0000-0003-0152-460X

Claudio Minero: 0000-0001-9484-130X

Alberto Tiraferri: 0000-0001-9859-1328

Davide Vione: 0000-0002-2841-5721

\section{Notes}

The authors declare no competing financial interest. 


\section{ACKNOWLEDGMENTS}

M.M. and D.V. are grateful to Compagnia di San Paolo and Universita di Torino for the financial support to the project CSTO168282-ABATEPHARM, which also supported SB's scholarship. The authors are thankful to Dr. Rita Binetti and Dr. Eugenio Lorenzi (SMAT S.p.A., Italy) for providing the real wastewater samples and for critically reading the manuscript.

\section{REFERENCES}

(1) Hammer, M. J., Sr.; Hammer, M. J., Jr. Water and Wastewater Technology, 7th ed.; Pearson: London, U.K., 2012.

(2) Petrie, B.; Barden, R.; Kasprzyk-Hordern, B. A review on emerging contaminants in wastewaters and the environment: Current knowledge, understudied areas and recommendations for future monitoring. Water Res. 2015, 72, 3-27.

(3) Richardson, S. D. Environmental Mass Spectrometry: Emerging Contaminants and Current Issues. Anal. Chem. 2012, 84, 747-778.

(4) Carvalho, R. N.; Ceriani, L.; Ippolito, A.; Lettieri, T. Development of the First Watch List under the Environmental Quality Standards Directive; Publications Office of the European Union: Luxembourg, 2015.

(5) Barbeni, M.; Minero, C.; Pelizzetti, E.; Borgarello, E.; Serpone, N. Chemical degradation of chlorophenols with Fenton's reagent ( $\mathrm{Fe} 2++\mathrm{H} 2 \mathrm{O} 2)$. Chemosphere 1987, 16, 2225-2237.

(6) Lipczynska-Kochany, E. Degradation of aqueous nitrophenols and nitrobenzene by means of the Fenton reaction. Chemosphere 1991, 22, 529-536.

(7) Maillard, C.; Guillard, C.; Pichat, P. Comparative effects of the $\mathrm{TiO} 2-\mathrm{UV}, \mathrm{H} 2 \mathrm{O} 2-\mathrm{UV}, \mathrm{H} 2 \mathrm{O} 2-\mathrm{Fe} 2+$ systems on the disappearance rate of benzamide and 4-hydroxybenzamide in water. Chemosphere 1992, 24, 1085-1094.

(8) Walling, C. Fenton's reagent revisited. Acc. Chem. Res. 1975, 8, 125-131.

(9) Vione, D.; Merlo, F.; Maurino, V.; Minero, C. Effect of humic acids on the Fenton degradation of phenol. Environ. Chem. Lett. 2004, 2, 129-133

(10) Minero, C.; Lucchiari, M.; Maurino, V.; Vione, D. A quantitative assessment of the production of $\cdot \mathrm{OH}$ and additional oxidants in the dark Fenton reaction: Fenton degradation of aromatic amines. RSC Adv. 2013, 3, 26443-26450.

(11) Brillas, E.; Sauleda, R.; Casado, J. Degradation of 4chlorophenol by anodic oxidation, electro-fenton, photoelectrofenton, and peroxi-coagulation processes. J. Electrochem. Soc. 1998, $145,759-765$.

(12) Tzedakis, T.; Savall, A.; Clifton, M. J. The electrochemical regeneration of Fenton's reagent in the hydroxylation of aromatic substrates: batch and continuous processes. J. Appl. Electrochem. 1989, 19, 911-921.

(13) Moreira, F. C.; Boaventura, R. A. R.; Brillas, E.; Vilar, V. J. P. Electrochemical advanced oxidation processes: $A$ review on their application to synthetic and real wastewaters. Appl. Catal., B 2017, 202, 217-261.

(14) Minella, M.; Marchetti, G.; De Laurentiis, E.; Malandrino, M.; Maurino, V.; Minero, C.; Vione, D.; Hanna, K. Photo-Fenton oxidation of phenol with magnetite as iron source. Appl. Catal., B 2014, 154-155, 102-109.

(15) Carlos, L.; Fabbri, D.; Capparelli, A. L.; Bianco Prevot, A.; Pramauro, E.; García Einschlag, F. Effect of simulated solar light on the autocatalytic degradation of nitrobenzene using $\mathrm{Fe} 3+$ and hydrogen peroxide. J. Photochem. Photobiol., A 2009, 201, 32-38.

(16) Chen, F.; Ma, W.; He, J.; Zhao, J. Fenton Degradation of Malachite Green Catalyzed by Aromatic Additives. J. Phys. Chem. A 2002, 106, 9485-9490.

(17) Huang, W.; Brigante, M.; Wu, F.; Hanna, K.; Mailhot, G. Development of a new homogenous photo-Fenton process using Fe(III)-EDDS complexes. J. Photochem. Photobiol., A 2012, 239, 1723.
(18) Wu, Y.; Passananti, M.; Brigante, M.; Dong, W.; Mailhot, G. $\mathrm{Fe}(\mathrm{III})$-EDDS complex in Fenton and Photo-Fenton processes: from the radical formation to the degradation of a target compound. Environ. Sci. Pollut. Res. 2014, 21, 12154-12162.

(19) Wei, T.-Y.; Wang, Y.-Y.; Wan, C.-C. Photocatalytic oxidation of phenol in the presence of hydrogen peroxide and titanium dioxide powders. J. Photochem. Photobiol., A 1990, 55, 115-126.

(20) Zepp, R. G.; Faust, B. C.; Hoigne, J. Hydroxyl Radical Formation in Aqueous Reactions ( $\mathrm{pH}$ 3-8) of Iron(II) with Hydrogen Peroxide: The Photo-Fenton Reaction. Environ. Sci. Technol. 1992, 26, 313-319.

(21) Ruppert, G.; Bauer, R.; Heisler, G.; Novalic, S. Mineralization of cyclic organic water contaminants by the photo-fenton reaction Influence of structure and substituents. Chemosphere 1993, 27, 13391347.

(22) Wink, D. A.; Nims, R. W.; Saavedra, J. E.; Utermahlen, W. E.; Ford, P. C. The Fenton oxidation mechanism: reactivities of biologically relevant substrates with two oxidizing intermediates differ from those predicted for the hydroxyl radical. Proc. Natl. Acad. Sci. U.S.A. 1994, 91, 6604-6608.

(23) Bossmann, S. H.; Oliveros, E.; Göb, S.; Siegwart, S.; Dahlen, E. P.; Payawan, L.; Straub, M., Jr; Wörner, M.; Braun, A. M. New Evidence against Hydroxyl Radicals as Reactive Intermediates in the Thermal and Photochemically Enhanced Fenton Reactions. J. Phys. Chem. A 1998, 102, 5542-5550.

(24) Deguillaume, L.; Leriche, M.; Chaumerliac, N. Impact of radical versus non-radical pathway in the Fenton chemistry on the iron redox cycle in clouds. Chemosphere 2005, 60, 718-724.

(25) Pignatello, J. J.; Liu, D.; Huston, P. Evidence for an Additional Oxidant in the Photoassisted Fenton Reaction. Environ. Sci. Technol. 1999, 33, 1832-1839.

(26) Vione, D.; Minella, M.; Maurino, V.; Minero, C. Indirect Photochemistry in Sunlit Surface Waters: Photoinduced Production of Reactive Transient Species. Chem.-Eur. J. 2014, 20, 1059010606.

(27) Martínez, F.; Calleja, G.; Melero, J. A.; Molina, R. Iron species incorporated over different silica supports for the heterogeneous photo-Fenton oxidation of phenol. Appl. Catal., B 2007, 70, 452-460.

(28) Ramírez, J.; Godínez, L. A.; Méndez, M.; Meas, Y.; Rodríguez, F. J. Heterogeneous photo-electro-Fenton process using different iron supporting materials. J. Appl. Electrochem. 2010, 40, 1729-1736.

(29) Minella, M.; Sappa, E.; Hanna, K.; Barsotti, F.; Maurino, V.; Minero, C.; Vione, D. Considerable Fenton and photo-Fenton reactivity of passivated zero-valent iron. RSC Adv. 2016, 6, 8675286761.

(30) Avetta, P.; Pensato, A.; Minella, M.; Malandrino, M.; Maurino, V.; Minero, C.; Hanna, K.; Vione, D. Activation of Persulfate by Irradiated Magnetite: Implications for the Degradation of Phenol under Heterogeneous Photo-Fenton-Like Conditions. Environ. Sci. Technol. 2015, 49, 1043-1050.

(31) Costa, A. R.; de Pinho, M. N. Performance and cost estimation of nanofiltration for surface water treatment in drinking water production. Desalination 2006, 196, 55-65.

(32) Demarchis, L.; Minella, M.; Nisticò, R.; Maurino, V.; Minero, C.; Vione, D. Photo-Fenton reaction in the presence of morphologically controlled hematite as iron source. J. Photochem. Photobiol., A 2015, 307-308, 99-107.

(33) Huang, H.-H.; Lu, M.-C.; Chen, J.-N. Catalytic decomposition of hydrogen peroxide and 2-chlorophenol with iron oxides. Water Res. 2001, 35, 2291-2299.

(34) Vilardi, G.; Sebastiani, D.; Miliziano, S.; Verdone, N.; Di Palma, L. Heterogeneous nZVI-induced Fenton oxidation process to enhance biodegradability of excavation by-products. Chem. Eng. J. 2018, 335, 309-320.

(35) Bergendahl, J. A.; Thies, T. P. Fenton's oxidation of MTBE with zero-valent iron. Water Res. 2004, 38, 327-334.

(36) Ahmed, M. M.; Barbati, S.; Doumenq, P.; Chiron, S. Sulfate radical anion oxidation of diclofenac and sulfamethoxazole for water decontamination. Chem. Eng. J. 2012, 197, 440-447. 
(37) Ji, Y.; Ferronato, C.; Salvador, A.; Yang, X.; Chovelon, J.-M. Degradation of ciprofloxacin and sulfamethoxazole by ferrousactivated persulfate: Implications for remediation of groundwater contaminated by antibiotics. Sci. Total Environ. 2014, 472, 800-808.

(38) Baker, R. W. Membrane Technology and Application, 3rd ed.; Wiley, 2012; pp 575.

(39) Chong, M. N.; Jin, B.; Chow, C. W. K.; Saint, C. Recent developments in photocatalytic water treatment technology: A review. Water Res. 2010, 44, 2997-3027.

(40) Ozgun, H.; Dereli, R. K.; Ersahin, M. E.; Kinaci, C.; Spanjers, H.; van Lier, J. B. A review of anaerobic membrane bioreactors for municipal wastewater treatment: integration options, limitations and expectations. Sep. Purif. Technol. 2013, 118, 89-104.

(41) Leiknes, T. The effect of coupling coagulation and flocculation with membrane filtration in water treatment: A review. J. Environ. Sci. 2009, 21, 8-12.

(42) Miralles-Cuevas, S.; Audino, F.; Oller, I.; Sánchez-Moreno, R.; Sánchez Pérez, J. A.; Malato, S. Pharmaceuticals removal from natural water by nanofiltration combined with advanced tertiary treatments (solar photo-Fenton, photo-Fenton-like $\mathrm{Fe}(\mathrm{III})$-EDDS complex and ozonation). Sep. Purif. Technol. 2014, 122, 515-522.

(43) Miralles-Cuevas, S.; Arqués, A.; Maldonado, M. I.; SánchezPérez, J. A.; Malato Rodríguez, S. Combined nanofiltration and photo-Fenton treatment of water containing micropollutants. Chem. Eng. J. 2013, 224, 89-95.

(44) Miralles-Cuevas, S.; Oller, I.; Pérez, J. A. S.; Malato, S. Removal of pharmaceuticals from MWTP effluent by nanofiltration and solar photo-Fenton using two different iron complexes at neutral $\mathrm{pH}$. Water Res. 2014, 64, 23-31.

(45) Xu, P.; Bellona, C.; Drewes, J. E. Fouling of nanofiltration and reverse osmosis membranes during municipal wastewater reclamation: Membrane autopsy results from pilot-scale investigations. J. Membr. Sci. 2010, 353, 111-121.

(46) Chon, K.; KyongShon, H.; Cho, J. Membrane bioreactor and nanofiltration hybrid system for reclamation of municipal wastewater: Removal of nutrients, organic matter and micropollutants. Bioresour. Technol. 2012, 122, 181-188.

(47) Buxton, G. V.; Greenstock, C. L.; Helman, W. P.; Ross, A. B. Critical Review of rate constants for reactions of hydrated electrons, hydrogen atoms and hydroxyl radicals $\left(\cdot \mathrm{OH} / \cdot \mathrm{O}^{-}\right.$in Aqueous Solution. J. Phys. Chem. Ref. Data 1988, 17, 513-886.

(48) De Laurentiis, E.; Chiron, S.; Kouras-Hadef, S.; Richard, C.; Minella, M.; Maurino, V.; Minero, C.; Vione, D. Photochemical Fate of Carbamazepine in Surface Freshwaters: Laboratory Measures and Modeling. Environ. Sci. Technol. 2012, 46, 8164-8173.

(49) Vilve, M.; Vilhunen, S.; Vepsäläinen, M.; Kurniawan, T. A.; Lehtonen, N.; Isomäki, H.; Sillanpää, M. Degradation of 1,2dichloroethane from wash water of ion-exchange resin using Fenton's oxidation. Environ. Sci. Pollut. Res. 2010, 17, 875-884.

(50) Lorenzi, E. Personal communication, January 2018. Eugenio Lorenzi is a WWTP manager (Castiglione Torinese WWTP, operated by SMAT SpA).

(51) Giannakis, S.; Gamarra Vives, F. A.; Grandjean, D.; Magnet, A.; De Alencastro, L. F.; Pulgarin, C. Effect of advanced oxidation processes on the micropollutants and the effluent organic matter contained in municipal wastewater previously treated by three different secondary methods. Water Res. 2015, 84, 295-306.

(52) Giannakis, S.; Hendaoui, I.; Rtimi, S.; Fürbringer, J.-M.; Pulgarin, C. Modeling and treatment optimization of pharmaceutically active compounds by the photo-Fenton process: The case of the antidepressant Venlafaxine. J. Environ. Chem. Eng. 2017, 5, 818-828. (53) Samhaber, W. M.; Nguyen, M. T. Applicability and costs of nanofiltration in combination with photocatalysis for the treatment of dye house effluents. Beilstein J. Nanotechnol. 2014, 5, 476-484.

(54) Costa, R.; Lelis, M.; Oliveira, L.; Fabris, J.; Ardisson, J.; Rios, R.; Silva, C.; Lago, R. Novel active heterogeneous Fenton system based on $\mathrm{Fe}_{3-\mathrm{x}} \mathrm{M}_{\mathrm{x}} \mathrm{O}_{4}(\mathrm{Fe}, \mathrm{Co}, \mathrm{Mn}, \mathrm{Ni})$ : The role of $\mathrm{M}^{2+}$ species on the reactivity towards $\mathrm{H}_{2} \mathrm{O}_{2}$ reactions. J. Hazard. Mater. 2006, 129, 171-178.
(55) Muñoz, I.; Fernández-Alba, A. R. Reducing the environmental impacts of reverse osmosis desalination by using brackish groundwater resources. Water Res. 2008, 42, 801-811. 